\title{
Análisis psicojurídico de la entrevista forense en el abordaje penal del abuso sexual
}

\section{infantil}

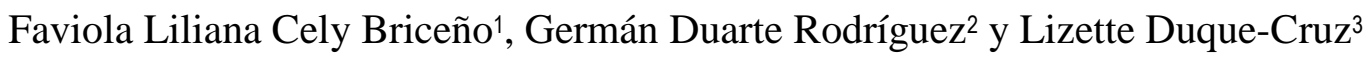

\section{Resumen}

El relato del menor presunta víctima de abuso sexual, cobra relevancia en la investigación del delito sexual en Colombia; su recaudo en el anterior sistema de justicia penal, se hacía por declaración indicada en el artículo 266 de la derogada Ley 600 de 2000, en el sistema vigente, mediante la entrevista que trata el artículo 206 de la ley 906 de 2004, que el ICBF documenta como "Entrevista Forense" (EF) desde 2007, configurándose vínculo entre este medio de conocimiento y el relato como medio de prueba en el proceso penal que hacen exigible un acto judicial revestido con precisas condiciones. El análisis de la EF en fuentes del derecho permite identificar vacíos e imprecisiones respecto a su definición, si se contrasta con la teoría aportada por la psicología del testimonio. En virtud de ello, la investigación de la que da cuenta este trabajo desarrolla un análisis psicojurídico a partir de tres fuentes de información primarias: jurisprudencia, lineamientos técnicos/guías y leyes, las cuales aportan datos en cuatro categorías preestablecidas: concepto, estructura, procedimiento y alcances, cuyos resultados dicen que aun con soporte teórico, recogido en varios protocolos reconocidos en la jurisprudencia, y tratada en ley específica, la EF es asumida como una llana formulación de preguntas incorrectas por ser preestablecidas, directivas, conductivas o sugestivas; que la tendencia jurisprudencial no acoge los reclamos para que se admita el debido proceso en ese acto; que no se consideran los efectos negativos que esto tiene sobre el recuerdo original, base del relato; y que se desconocen sus

\footnotetext{
${ }^{1}$ Faviola Cely, email: celybric@gmail.com

${ }^{2}$ Germán Duarte, email: psicoduarte@gmail.com

${ }^{3}$ Lizette Duque-Cruz, Facultad de Psicología, Universidad Santo Tomás, email: lizetteduque@santotomas.edu.co
} 
ENTREVISTA FORSENSE Y ABUSO SEXUAL INFANTIL

condiciones técnico-científicas, en detrimento de una adecuada praxis de la EF en el derecho penal.

\title{
Palabras clave
}

Entrevista forense, psicología del testimonio, abuso sexual infantil, proceso penal y prueba penal.

\begin{abstract}
Legal acts arranged in the procedural statutes are essential to the criminal proceeding against child sex crime in Colombia, raise the story of the child is constituted in one of those. The repealed Law 600 of 2000 article 266 it was taken by declaration, in the current Law 906 of 2004 article 206, emerges the interview, which in 2007 is called "Forensic Interview" (EF), configuring link between this knowledge and story as evidence in the evidentiary debate demanding a judicial act containing specific conditions. The standard analysis identifies gaps and inaccuracies regarding its definition, if contrasted with the theory provided by the psychology of testimony. Under this, the investigation that realizes this work develops a psycho-legal analysis from three primary sources of information: jurisprudence, technical guidelines / guides and laws, which provide data on four preset categories: concept, structure, procedure and scope, the results say that even with theoretical support, collected in various protocols renowned in jurisprudence, and treated in specific law, the EF is assumed as a plain incorrect formulation of preset questions, directives, conductive or suggestive; jurisprudential trend that does not accept the claims that due process be admitted in this event; not considered the negative effects this has on the original memory, the basis of the story; and its technical and scientific conditions are unknown at the expense of proper practice of criminal law.
\end{abstract}




\section{Keywords}

Forensic interview, psychology of testimony, child sexual abuse and criminal trial process.

\section{Introducción}

El Abuso Sexual Infantil (ASI) tiene un abordaje desde el derecho penal, en este el testimonio de su víctima constituye un elemento de esencial valor probatorio otorgado por el juez, por lo cual es una temática no solo de interés para los tratadistas del derecho penal sino también para los profesionales lo recaudan y le dan alcance forense a través de opiniones; al testimonio ofrecido en juicio, le antecede procesalmente el relato infantil obtenido con la EF y ambos, relato y testimonio constituyen una unidad que el juez toma junto a otras pruebas, para determinar la ocurrencia del hecho y eventual responsabilidad del procesado.

La realidad jurisprudencial, se requiere de un análisis cronológico sobre la EF como medio de conocimiento del relato ofrecido por el menor como prueba del ASI, luego de la revelación y noticia criminis, para ver si aquella, la EF, se vislumbra como la garantía igualitaria de los derechos fundamentales de las partes en conflicto, predicada en sentencias como la C-177/2014.

Entonces, cuando el ASI se toma como la entidad delictiva estatuida en los artículos 205 a 219 de la Ley 599/2000, Código Penal Colombiano (CPC), está sujeto a probanza; surge el proceso penal, fundamentado en principios de raigambre constitucional como el de igualdad, imparcialidad, inocencia y contradicción, luego, por crudo y desobligado que parezca, jurídicamente no se puede obviar someter a prueba de verdad el dicho del menor bajo el entendido que llegar a la verdad objetiva es principio del sistema de justicia referida en los artículos 5, 11, 111, 336 del CP y que ello es factible por el ejercicio probatorio de las partes, que, retomando a Dukala y Polczyk (2014), es establecer si la alegación es verdadera o falsa, lo

que significa que desde lo testimoniado por el NNA, en diferentes entrevistas como la EF, las 
partes procesales buscan evidencias internas (propias del relato) y externas (evidencias trazas, físicas, etc.) que les permita probar o desestimar el hecho.

Atinente a lo mismo la C-177/2014, citando la C-1260/2005:

“...en la etapa de investigación no se practican realmente pruebas sino que, tanto

la Fiscalía como la defensa, recaudan elementos materiales probatorios y evidencias físicas, las cuales habrán de descubrirse en el momento de la acusación para ser practicadas en el juicio, tanto los favorables como los desfavorables al procesado, por lo que no puede considerarse que se violan los principios de publicidad y defensa." (cursivas dentro del texto)

La prueba, en el contexto del abordaje psicojurídico del ASI, es un punto de partida para el desarrollo de esta investigación, al observar que un delito de privacidad, por lo general testigos, varias veces sin testigos ni evidencia física del evento, como sucede ante actos abusivos, erige esencial la prueba testimonial para probar el delito y su autoría, como lo ha reiterado la jurisprudencia de Colombia al discutir la credibilidad o valor probatorio del testimonio infantil; para ilustrar, la Sala Penal de la Corte Suprema de Justicia, en sentencia C-23706/2006, Magistrada Ponente (MP) Marina Pulido de Barón, citada por Espinosa (2012), y por Polo y Cabarcas (2013), indicó: “De acuerdo con investigaciones de innegable carácter científico, se ha establecido que cuando él menor es la víctima de atropellos sexuales su dicho adquiere una especial confiabilidad...”, línea jurisprudencial citada en otras sentencias como los Radicados C29678/2008, C-29369/2010 de la misma Corte y la T-078/2010 de la Corte Constitucional.

Simultáneamente, en revisión de los códigos procesales penales de Colombia (CPP) se identifica insuficiente regulación que oriente la debida toma del relato infantil; para esto se recurre a la entrevista, pero la experiencia permite señalar que su práctica no se ajusta a 
estándares técnicos-científicos exigidos para un acto judicial, potencial prueba en el proceso penal.

Junto a esa falta de rigor, suelen convenir circunstancias dispendiosas tanto para las partes en conflicto, como para el principio de mismidad (conservación inalterable) de la prueba, ya que la memoria humana, base del testimonio, puede verse afectada o distorsionada ante improcedentes medios de recuperación del recuerdo, como lo sugiere Soria (2007, pp. 97-99); se menoscaban garantías y derechos de los actores y del proceso penal.

Por lo anterior, las preguntas de la investigación fueron: ¿cuál es el análisis psicojurídico que la ley y la jurisprudencia de Colombia le ha dado a la EF en el marco de la investigación penal del ASI?, y ¿cuál es el concepto, la estructura, el procedimiento y los alcances de la ley la jurisprudencia de Colombia para la EF, en el marco de la investigación penal del ASI?

En punto a responder esto se tiene por análisis psicojurídico, una lectura desde la psicología del testimonio sobre aquellas disposiciones emanadas de la ley y la jurisprudencia en torno a ese acto jurídico denominado EF.

Como objetivo general se propuso: inferir el concepto, estructura, procedimiento y alcances a través de un análisis psicojurídico de la ley y jurisprudencia de Colombia respecto a la recepción del testimonio al menor presunta víctima en la investigación penal del ASI; y como objetivos específicos: contextualizar en el histórico de las normas penales y procesales penales de Colombia el uso de la entrevista en la recepción del testimonio del menor presunta víctima de ASI; identificar guías, reglamentos, lineamientos técnicos, leyes y jurisprudencia que existan en Colombia sobre EF para menores víctimas de ASI, con el fin de destacar y discriminar características relativas al concepto, estructura, procedimiento y alcances que se le da; deducir la relación entre las características halladas para la EF y las aportadas por la psicología sobre el 
testimonio infantil; y finalmente, aportar recomendaciones que permitan considerar la necesidad de reformular la regulación de la entrevista forense en la investigación del delito de ASI, para una adecuada praxis.

\section{Método}

\section{Enfoque.}

El estudio asumió un enfoque cualitativo que, de acuerdo con Cifuentes (2011) y Hernández, Fernández y Baptista (2010), se interesa en aprehender realidades que aceptan diferentes apreciaciones; son relativas, particulares y cambiantes conforme a los contextos y actores intervinientes, lo que ocurre en el caso de Colombia para la EF usada en el proceso penal del ASI, donde su definición conceptual y operativa adquirió matices propios por la intervención de quienes participan en su ejecución, valuada mediante la observación, descripción e interpretación con miras a reconstruir la realidad.

En el análisis psicojurídico y la interpretación de los datos no se requirió tratamiento estadístico porque se basó en la comprensión y deducción de significados que el saber jurídico, legal y técnico le han imprimido al asunto de la EF, al servicio de lo cual los aportes de la psicología del testimonio se tornaron indispensables por sus propuestas en el tema del testimonio infantil.

\section{Diseño.}

Consonante con el enfoque cualitativo, se adoptó un diseño fenomenológico habilitado para aprehender percepciones y significados que las personas le atribuyen a una experiencia o fenómeno particular, según afirma Mertens (2005) y se reafirma a partir de Creswell (1998) y Álvarez-Gayou (2003) (como se citó en Hernández et al., 2010); las percepciones y significados 
frente a la EF fueron traídas a la jurisprudencia por quienes materializan la EF en el ejercicio cotidiano del derecho penal y acopiadas por los jueces

\section{Técnica.}

Como la EF irrumpe en la práctica del derecho penal y procesal penal, su definición global, matices y significado fueron ensamblándose en diversos documentos públicos; se eligió la revisión documental como una de las técnicas pertinentes al estudio.

En armonía, se dio el análisis de contenido, que como diría Piñuel (2002), permitió desvelar el significado o sentido atribuible al tema central de análisis, "de forma que una nueva interpretación tomando en cuenta los datos del análisis, permitiría un diagnóstico, es decir, un nuevo conocimiento (gnoscere "conocer") a través de su penetración intelectual". (p. 2) No se trata simplemente de incorporar al estudio el dato inmerso en las unidades de análisis, sino escudriñar el sentido que adquirió la EF en el ejercicio del derecho penal.

Se retomó el contenido específico inmerso en las unidades de análisis, con técnicas acordes con los tres niveles de lenguaje que según Ruiz (2004) operan en el análisis de contenido:

"El nivel interpretativo consiste en la capacidad que tiene el investigador de comprender el sentido de la información a la que ha accedido (nivel de superficie) y ha organizado (nivel analítico), y a la que también ha dotado de un sentido nuevo" (p. 46).

Para el autor el nivel de superficie está constituido por las afirmaciones, preguntas y demás formulaciones en entrevista individual o colectiva, o presentes en testimonio escrito, el nivel analítico se lograr al ordenar estas formulaciones desde criterios de afinidad o de diferenciación y al construir categorías para clasificar y organizar la información, conjugándose así el análisis de contenido. 
Como técnicas se utilizaron, para el primer nivel, lectura libre que permitió resaltar en el texto total la información pertinente al tema; el fichaje textual para el segundo nivel, posibilitó consolidar la información destacada para posterior análisis crítico y; matrices de ponderación para el nivel interpretativo que posibilitaron clasificar datos conforme a las unidades y categorías propuestas (descritas adelante) e iniciar el proceso interpretativo, que se perfeccionó con la matriz de análisis comparativa, que permitió agrupar los resultados por categorías caracterizando todas las unidades y cumplimentar el análisis psicojurídico.

\section{Fuentes.}

Fueron documentales primarias y secundarias, las primeras, material escrito como leyes, sentencias y documentos técnicos, originados dentro de la institucionalidad por entes estatales como Rama Judicial, Legislativa, y el Instituto Nacional de Bienestar Familiar (ICBF), elegidas por plasmar criterios u opiniones sobre el asunto tratado que, al estar publicados, fueron de asequible consulta; las secundarias, refirieron al material bibliográfico especializado desde la psicología del testimonio y las ciencias jurídicas y contribuyeron a comprender la realidad por descubrir, consultar propuestas y experiencias consolidadas en otras latitudes asociadas a protocolos y guías.

\section{Unidades de análisis.}

Se seleccionaron tres, cada una dividida en categorías en las que se distinguieron dos tipos de atributos: legales y psicológicos. Se consideraron unos elementos emergentes, esto es, información que sin pertenecer a ninguna unidad de análisis se observó útil para entender el discurso.

(a) Unidad Jurisprudencial (UJ): sentencias o autos proferidos por la Corte Suprema de Justicia y la Corte Constitucional; exponen casuística generada sobre la EF y mostraron la 
interpretación dada a la ley por el operador judicial (no se tuvo en cuenta sentido del fallo). Integrada por 37 elementos.

(b) Unidad Técnica (UT): guías, reglamentos y lineamientos técnicos surgidos frente a la interinstitucionalidad e interdisciplinariedad inherente al modelo de atención integral del ASI, que tiene Colombia y acogidos por resoluciones. Integrada por 5 elementos.

(c) Unidad Legal (UL): Códigos y leyes con articulados referidos al testimonio desde 1920, se encontraron dos específicas al testimonio infantil, Ley 1098/2006, recogida en la Ley 1652/2013, que fue la examinada.

\section{Categorías orientadoras}

Fueron aspectos pensados como integrados en la definición de la EF; su presencia se escudriñó para cada unidad de análisis; se buscó información que respondiera a:

(a) Concepto: "El qué es".

(b) Estructura: "Conformada por".

(c) Procedimiento: "Cómo se hace".

(d) Alcances: "Para qué sirve".

\section{Atributos.}

Fueron subcategorías que condujeron la mirada psicojurídica del estudio abordado:

(a) Legales (AL): Impuestos por la ley; que condicionan a la característica.

(b) Psicológicos (AP): Conceptos o referentes psicológicos (edad, memoria, desarrollo cognitivo, etc.).

\section{Procedimiento.}

La investigación comprendió las siguientes etapas: 
(a) Descriptiva: se identificaron y seleccionaron documentos que conformaron las unidades de análisis; se usó búsqueda en sistemas de consulta vía web de la rama judicial y el ICBF; los documentos identificados se enlistaron, chequearon y sometieron a lectura para resaltar los apartados relevantes por contener información relacionada con las categorías.

(b) Clasificación y análisis: comprendió una nueva lectura de la información destacada con el uso de fichas textuales; en ella se clasificaron los datos por categorías y atributos; se condensó la información en las matrices de análisis para considerarla por unidades, y luego en conjunto.

(c) Co-construcción del significado: los resultados fueron sometidos a un análisis crítico con mirada psicojurídica, que conjugó aquellos saberes especializados de la psicología del testimonio y la experiencia profesional de los autores en escenarios de debate penal del ASI, para propiciar elementos teóricos que faciliten re-significar la EF en el escenario penal.

\section{Escenario cronológico}

La génesis y evolución de las leyes penales y procesales relacionadas con el testimonio, que recoge la entrevista a menores en Colombia, data de 1837, cuando según Bernate (2004) se promulgó el primer Código de Procedimiento Penal (CPP), que rigió a la Confederación Granadina; con la constitución de 1886, la patria se consolida como Estado unitario y el Código vigente desde 1858 (reproducción del de 1837), mutó al Código Penal -Ley 57/1887-, que rigió desde 1890, convirtiéndose en Ley 109/1922 de la Republica sin cobrar vigencia por estar descontextualizada. Años e intentos después, en 1936, se promulgó el Código Penal Colombiano (CP) -Ley 95-, que rigió hasta 1980; en los artículos 224 a 245 ya se reconocen derivaciones del concepto "testimonio" y reglas de aplicación: obligaciones y excepciones al deber de declarar, promesa legal del juramento, quién estaba facultado para interrogar, a quién correspondía su apreciación sobre credibilidad de testigos; particularmente sugiere algunos elementos técnicos 
como que al interrogatorio debía anteceder recepcionar un relato espontáneo, sin insinuar ni direccionar respuestas a testigos y consignar fielmente la información recabada, permitiendo aclarar con preguntas adicionales y contrainterrogatorios, sin embargo habiendo tratado lo atinente al testimonio, no invoca reglas especiales para la recepción y apreciación del testimonio infantil; de resaltar, la promoción de principios de objetividad e imparcialidad al instar a funcionarios de instrucción a investigar no sólo las circunstancias que establecieran y agravaran la responsabilidad del procesado, sino también aquellas que la eximieran, extinguieran o atenuaran.

Posteriormente surge el Decreto Ley 100/1980 incorporando el delito de incesto (artículo 259), durante su vigencia el procedimiento penal estuvo definido por los Decretos 50/1987 y 2700/1991; ambos admitieron el testimonio como medio de prueba, en general mantuvieron los criterios de recaudo ya mencionados, adicionando otros como la conservación del relato por cualquier medio electrónico, mecánico o técnico para su posterior examen y apreciación; en este no se arguye la premisa del relato espontáneo del hecho antes del interrogatorio, ni el de no condicionar su redacción, sin embargo, tanto aquí como en las leyes de la jurisdicción de menores (98/1920, 15/1923, 48/1924, 15/1925, 79/1926 y Decreto 2737/1989) persiste en el limbo jurídico la recepción del testimonio infantil, tan solo indicando la excepción de juramentar al testigo menor de 12 años.

A la Ley 100 le sobreviene la 599/2000 CP vigente, éste trata de los delitos sexuales relacionados con el ASI, artículos 205 al 219; simultáneamente se promulgó la Ley 600/2000 o $\mathrm{CPP}$, que al entrar en vigencia el sistema penal de tendencia oral acusatoria, se modificó por la Ley 906/2004, con la que emerge el uso de la entrevista como medio de aprehensión del fenómeno delictual (artículo 206), y cuyo uso en la obtención del relato infantil empieza a 
desarrollarse a través de la jurisprudencia, luego complementada con la Ley 1652/2013 “Por medio de la cual se dictan disposiciones acerca de la entrevista y el testimonio en procesos penales de niños, niñas y adolescentes víctimas de delitos contra la libertad, integridad y formación sexuales"; ley que adiciona el artículo 206A justamente el que introduce en el ordenamiento legal colombiano la entrevista forense en NNA víctimas de violencia sexual.

Cabe advertir la existencia de otros entes normativos: Ley 360/1997 origen de los Centros de Atención Integral a Víctimas de Abuso Sexual (CAIVAS), Guía de Atención a niños, niñas y adolescentes víctimas de violencia sexual (ICBF y OIM, 2007) y Resolución 6022/2010 ICBF, aprobando el "Lineamiento Técnico para el programa de atención a niños, niñas y adolescentes, víctimas de violencia sexual, con sus derechos amenazados, inobservados o vulnerados”, entre otros, por guardar relación con el modelo de atención integral a víctimas de ASI adoptado en Colombia; pese a estar taxativamente señalados, se entremezclan roles y competencias en el abordaje penal del fenómeno, que problematizan la praxis.

Por otra parte, al estimar la entrevista como técnica de recolección de información, desde la perspectiva de la psicología del testimonio y recurriendo a autores como Juárez y Sala (2011), puede entenderse a la EF como una actividad centrada en entrevistar a niños que han vivido una situación traumática como es el ASI, que “...puede ser una práctica dentro del marco judicial especifico de apoyo al juez/za, magistrado/da para tomar la primera declaración judicial del niño" (P. 9).

Para estos autores, a la EF le resulta pertinente un protocolo que observe indefectiblemente eon-dos condiciones; "facilitar y homogenizar la práctica” e incrementar las garantías en cuanto a que la información, obtenida mediante esta entrevista, atiende a un proceso que citando a Bunge (1981) debe ser "racional, sistemático, exacto, verificable y fiable", como garantía que las 
valoraciones e inferencias devenidas de esa información, se compaginan al conocimiento científico, propio de la actividad forense.

En ese mismo sentido se aprecian los aportes que según como Hernández y Tapias (2010) traen los protocolos y guías de EF como el de Michigan, Satac y Paso a Paso; "pretenden optimizar la calidad del entrevistador en la obtención de información específica para el proceso y con la menor contaminación posible" (P. 409); agregan que estos presuponen un riguroso procedimiento definido por etapas, con formas adecuadas de preguntar que descarta el uso de algunas preguntas, como por ejemplo las que inducen respuesta.

\section{Resultados}

Se relacionaron antes las unidades, categorías y atributos convenidos para este estudio, ahora se referirán los resultados obtenidos siguiendo el esquema descrito en la Figura 1. 


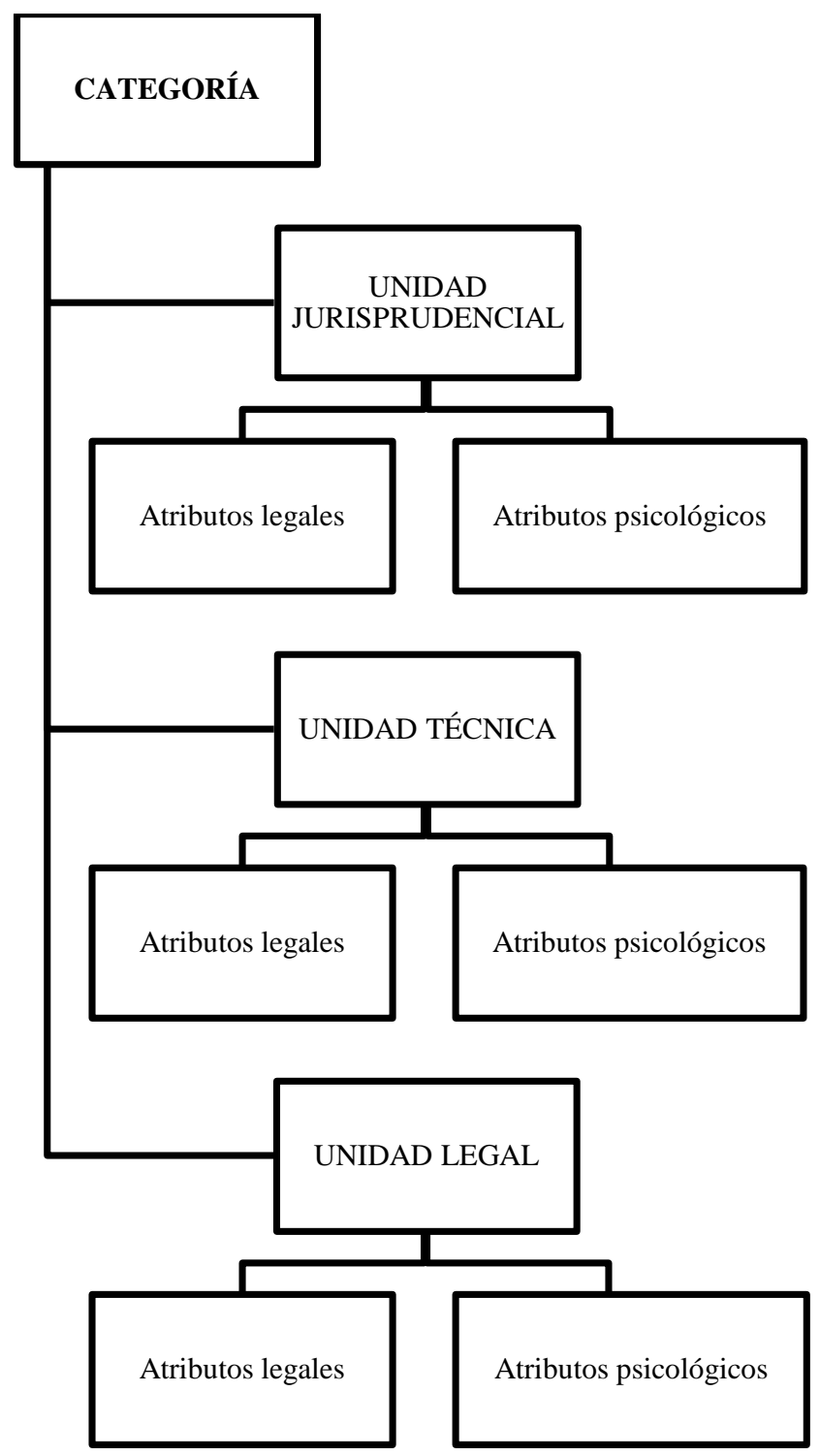

Figural. Esquema de condensación y análisis de cada una de las categorías a partir de las Unidades establecidas y según sus atributos legales y psicológicos.

\section{Categoría Concepto.}

A nivel de la UJ, aportan los pronunciamiento en sede de Casación penal ( C) o de Tutela (T): C-24468/06, C-31475/09, C-30355/09, C-28923/09, T-078/10, C-32829/10, C-34568/11, C35668/11, C-44066/14, TCivil-8509/15, Corte Constitucional-Sala Especial Auto-009/15, C45302/15, C-45141/15, T- 177/15. 
Tabla 1

Atributos legales y psicológicos de la categoría Concepto en la jurisprudencia de Colombia

\begin{tabular}{ll}
\hline AL & AP \\
\hline - Declaración de aspectos observados y percibidos & $\begin{array}{l}\text { - Entrevista psicológica (EP) efectuada en la fase } \\
\text { de investigación; }\end{array}$ \\
en forma directa; & $\begin{array}{l}\text { - Permite obtener relato del suceso abusivo; } \\
\text { - Elemento de conocimiento que contiene el relato, } \\
\text { plasmado en documento escrito; }\end{array}$ \\
- Entrevista recepcionada por funcionario de policía & - EP poede otorgársele la condición de testimonio; \\
judicial (PJ); & serie de manifestaciones que aquel debe escuchar \\
- Medios de convicción practicados durante & y registrar en su informe; \\
indagación e investigación; & \\
- Relato dado ante psicólogo CTI; & \\
- Entrevista Psicológica Judicial (EPJ); & \\
- Entrevista Forense (EF); & \\
\hline
\end{tabular}

A nivel de UT, respecto a AL y AP, describe única referencia en la Guía de Atención a Niños, Niñas, Adolescentes Víctimas de Violencia Sexual ICBF (2007); la cual toma indistintamente EF y EJ: “...una entrevista (en cámara de Gesell), donde se recogen las pruebas judiciales necesarias en contra del agresor...", aceptada en casos de niños objeto de abuso. Busca obtener la mayor cantidad de información, incluyendo también objetivos terapéuticos y selectividad de evidencias.

A nivel de UL, no se hallaron referentes sobre esta categoría.

\section{Categoría Estructura.}

Manifestada en los fallos: T-458/07, T-078/10, C-29369/10, C-44066/14, C-45141/15, T177/15, C-47303/16/.

Respecto a AL: "Presentación completa de los hechos de la causa" e insinuaciones a estructura, estilo y formato pregunta-respuesta, prototipo de declaración y lenguaje jurídico (“Sírvase indicar...", "Dígale a este...", "Diga usted...”). No define elementos para AP. 
A nivel de UT solo aporta en la Guía (2007) mencionada, en este caso datos aplicables a AP, como los componentes de la EF: Planeación y preparación; construir una relación de empatía; introducir el tema; preguntas abiertas; preguntas específicas, cierre.

A nivel de UL, la simplifica a cuestionario de preguntas pre-elaboradas, ubicada en AL.

\section{Categoría Procedimiento.}

Manifestada en los fallos: C-23706/06, C-24468/06, C-29053/08, C-29117/08, C32099/09, C-32595/09, T-078/10, C-32872/10, T-117/13, C-32868/10, C-32829/10,C- 33010/10, C-29369/10, T-843/11, Corte Constitucional-Sala Especial Auto-009/15 , C-45435/15, TC8509/15, C-45141/15, T-177/15, 43866/16.

Se aducen actos positivos (hacer) y negativos (no hacer), y advierte condiciones propias.

Tabla 2

Atributos legales y psicológicos de la categoría Procedimiento en la jurisprudencia de Colombia

\begin{tabular}{ll}
\hline AL & AP \\
\hline Positivos & \\
\hline - Primero escuchar, luego interrogar al testigo; & - Toma de consentimiento informado; \\
& - Determinar capacidad psicoperceptiva al \\
& entrevistado, raciocinio mínimo para declarar; \\
& - Permitir al menor contar historia con sus propias \\
& palabras y términos; \\
& - Formular preguntas correctas; \\
& - Ahondar en detalles; \\
& $\begin{array}{l}\text { - Admite el uso correcto de protocolos, porque } \\
\text { permiten ahondar en detalles y circunstancias del }\end{array}$ \\
& hecho; \\
& - Entrevista semiestructurada; \\
\hline Negativos & \\
\hline - Resulta exiguo juramentar menores de 12 años; & - Formular preguntas sugestivas, tendenciosas, \\
- Advertencias relativas al deber de declarar, no & dirigidas, pueden confundir o llevar a error en los \\
necesarias. & informes; \\
- Formulación de preguntas incorrectas: sugestivas, & \\
capciosas; & \\
\hline Condiciones & \\
\hline - Ambiente controlado; & \\
\hline - Testimonio puerta cerrada; & - Uso de método técnico científico; \\
\hline
\end{tabular}


ENTREVISTA FORSENSE Y ABUSO SEXUAL INFANTIL

- Uso correcto de protocolos;

forense, da validez científica al procedimiento.

- Refiere como normas reguladoras, artículos 150 y

194 de la Ley 1098 de 2006;

En la UT aportan a la Categoría Procedimiento los elementos Guía/2007 y Lineamiento técnico (Res. 6022/10) ICBF.

Tabla 3

Atributos legales y psicológicos de la categoría Procedimiento en la Unidad Técnica

\begin{tabular}{ll}
\hline AL & AP \\
\hline - Defensorías de Familia deben remitir para la & - Protocolo Satac (CornerHouse); \\
realización de acciones como la EF & - Permitirle a menores contar historia con sus \\
- Psicólogos de CTI, SIJIN, toman la EF en Cámara & propias palabras y términos; \\
de Gessell, con Defensor de Familia desde zona de & - Generar empatía antes de entrar de lleno en tema \\
grabación, excepcionalmente pueden apoyar & del abuso; \\
profesionales de Equipos Interdisciplinarios del & - Comenzar discutiendo tópicos comunes no \\
ICBF, que hayan recibido la capacitación en EF; & sexuales; \\
& - Determinar nivel de comprensión y terminología \\
& para describir partes del cuerpo y sus funciones; \\
& - Captar lenguaje del menor, adaptarse a él según \\
& maduración y desarrollo cognitivo; \\
& - Comenzar con preguntas semidirigidas, luego \\
más directas para expandir o clarificar ciertas & áreas, si se considera necesario; \\
- Entrevistar al niño o niña solo, si es posible; & - Escucha activa que permita explorar y entender \\
& lo dicho antes;
\end{tabular}

Negativos

- Evitar entrevistas múltiples y prolongadas;

- El psicólogo que realiza EF, no debe intervenir en tratamiento terapéutico.

- Evitar que el menor presencie la descripción del adulto, acerca de lo que ocurrió;

\section{Categoría Alcances.}

Manifestada en los fallos: T-0554/03, C-23706/06, C-24468/06, T-458/07, C-29117/08, C-

29053/08, C-31475/09, C-30355/09, C-32099/09, C-28923/09, C-32595/09, T-078/10, C-

32872/10, T-117/13, C-32868/10, C-32829/10, C-33928/10, C-33010/10, C-29369/10, C- 
ENTREVISTA FORSENSE Y ABUSO SEXUAL INFANTIL

34508/10, C-34568/11, C-35668/11, T-843/11, C-44066/14, Corte Constitucional-Sala Especial

Auto-009/15, 43213/15, 43618/15, 45435/15, TC-8509/15, 45141/15, T-177/15, 43866/16.

Tabla 4

Atributos legales y psicológicos de la categoría Alcances en la jurisprudencia de Colombia

\begin{tabular}{ll}
\hline AL & AP \\
\hline - Prueba indiciaria, testimonial, esencial, testifical, & - Capacidad del menor como testigo, no afectada \\
de referencia, directa e indirecta, no es autónoma; & por inmadurez, sugestionabilidad, capacidad \\
- El testimonio del menor con vocación/valor & imaginativa o por ser usual que mientan; \\
probatorio suficiente; & - Obtener narración objetiva; \\
- Credibilidad y confiabilidad del relato, no afectada & - Validez y credibilidad del testimonio mediante \\
por denuncia tardía, ni por contradicción en & evaluación "Forense", bajo criterios de coherencia, \\
versiones; & ausencia de contradicciones e inconsistencias, \\
- Entrevista como elemento de conocimiento, sin & $\begin{array}{l}\text { respaldo afectivo, detalles específicos, estabilidad } \\
\text { calidad de testimonio; }\end{array}$ \\
- Relato y testimonio forman unidad; valoración & - Psicólogos entrevistadores forenses aportan \\
conjunta; & prueba técnica pericial; \\
- Incorporación a juicio de E.F.; & - Perito Psicólogo como órgano de prueba; \\
- Error de hecho por falso juicio de identidad; & - E.P.J. permitió inferir estado de incapacidad de \\
- Registro técnico audiovisual; & resistir; \\
& - Evitar revictimización; \\
& - Registro técnico audiovisual; \\
\hline
\end{tabular}

A nivel de UT, la Guía del ICBF (2007) indica que las EF aportan criterios de “participación en el veredicto y convalidación del relato del niño, supeditado al conocimiento, comprensión y habilidad del profesional que le asista y sus capacidades argumentativas de razonamiento y discernimiento sobre la ocurrencia del ASI".

A nivel de UL, para la postulación legal excepcional, para ser usada como prueba de referencia, suman los elementos emergentes, que guardan relación con situaciones de indefensión, protección derechos fundamentales, condiciones de coacción, presiones psicológicas y familiares para declarar o no hacerlo; características del entrevistador forense (debido entrenamiento, neutralidad, diligencia, sin coaccionar testigos), para el caso de la UJ. 
ENTREVISTA FORSENSE Y ABUSO SEXUAL INFANTIL

Respecto a la UT, realza competencias institucionales y roles de funcionarios ante fenómeno del ASI, que conforman el modelo de atención integral a menores presuntas víctimas, en especial lo que corresponde a la EF.

\section{Discusión}

Con los resultados identificados, se exponen las inferencias que permiten las afirmaciones contenidas en las unidades de análisis, siguiendo el esquema propuesto.

Cabe indicar que aun cuando el concepto general de testimonio, como narración de hechos pasados conocidos por los órganos de los sentidos por haberse vivido, visto o escuchado, es válido para el derecho y la psicología; hay diferencia, no ya de concepto, sino de oportunidad de aplicación del término, pues para el derecho el testimonio emerge a la vida jurídica en tanto es prueba practicada en momento procesal oportuno, divergencia no aplicada para la psicología.

Esta diferencia puede propiciar controversias innecesarias, por lo que se estipula acoger la distinción que hace el derecho entre relato (versiones previas sobre los hechos) y testimonio (usado en la fase conclusiva del proceso penal).

De otra parte conviene señalar una significativa relevancia en lo que respecta a lo hallado a nivel jurisprudencial frente al tema de la EF, ya que al ser esta fuente del derecho, permiten la entronización de sus predicamentos, definiendo líneas de reiterada consulta y observancia frente a todas las categorías aquí consideradas, como se ve en adelante.

\section{Categoría concepto.}


Ninguna de las unidades aporta información suficiente que permita una definición precisa y diferenciadora de la EF; hay aportaciones rescatables a la comprensión de aquella para el caso de Colombia.

La UL no ofrece definición diáfana de la EF, como técnica de recolección del relato o testimonio infantil en la investigación del delito sexual. Si bien la jurisprudencia consultada advierte que es la que permite la obtención de aquel, admite y nuestra conexas a aquella las entrevistas recepcionadas al NNA en el marco del examen forense médico, psicológico, psiquiátrico en buen número de sentencias examinadas.

Se advierten dificultades para conciliar la definición de EF referenciada desde la psicología del testimonio con la que emerge en la práctica del proceso penal, incluso desde el anterior sistema, acuñándose nombres inapropiados como: declaración, entrevista psicológica, psicológica judicial, semi-estructurada.

Común a esas denominaciones avaladas jurisprudencialmente es que son actos de investigación que por abordar el relato infantil parecen sugerir cumplido el objetivo de la EF, se admite su uso y la valía del relato obtenido sin juzgar las condiciones científicas evidenciadas por Juárez y Salas (2011),

Cierto es que no gozan de tales, porque conceptual y teóricamente son inexistentes para el mundo del conocimiento, como la mal llamada "psicológica judicial", hibrido fruto de la praxis, o, porque aun conviniendo su existencia, como la psicológica o la judicial, su uso y objetivo no se muestran afines al propósito, como ilustran tanto Arce y Fariña (2012, p. 2), al indicar que el formato de entrevistas policiales (judiciales para Colombia) no es validado para fines evaluativos, como el Instituto Nacional de Medicina Legal y Ciencias Forenses, INMLCF (s.f.), 
en las definiciones apropiadas por acuerdo de la Mesa Interinstitucional sobre el "Rol del Psicólogo en Relación con el Sistema Judicial”.

Entre las admitidas y sugeridas, Hernández y Tapias (2010) citan los protocolos forenses del Estado de Michigan (1996), SATAC y Paso a Paso; la entrevista cognitiva para Arce y Fariña (2006), e igualmente se consideraría el Protocolo NICHD (2007), referenciado por la Guía de Entrevista GEV de la Fiscalía Nacional del Ministerio Público de Chile (Maffioletti y Huerta, (2012).

Desde la óptica de la psicología, estos protocolos favorecen controlar factores incidentes al acceder al relato infantil, correspondientes con narración libre, libre de interferencias, lo más fiel y detallada posible, que luego con otros elementos permitan al juez un juicio de valor imparcial y objetivo respecto del hecho, aspectos no garantizados en las denominaciones halladas.

Los protocolos forenses frente a las entrevistas acuñadas jurisprudencialmente, por ser técnicas, dan mayor precisión y profundidad al relato, contrastan hipótesis, aclaran y amplían detalles, arrojando datos confiables. De allí el reparo al uso indiscriminado de esas expresiones nominales, que al no resultar técnicamente admitidas, rompen incluso reglas del testimonio expuestas en normatividad anterior a la vigente Ley 906/2004, artículo 206 del CPP, que hablan de una entrevista efectuada observando las reglas técnicas pertinentes y con la preservación de la prueba, los "recuerdos", por contaminación (Colwell, Hiscock y Memon, 2002; Yuille, Hunter, Joffe y Zaparniuk, 1993, citados por Arce y Fariña, 2012).

Dentro de la UT, los lineamientos observados no brindan una descripción específica más allá de expresiones como “...una entrevista (en cámara de Gesell), donde se recogen las pruebas judiciales necesarias en contra del agresor...” “...esta entrevista es aceptada en casos de niños sujetos a abuso. Busca obtener la mayor cantidad de información, teniendo también objetivos 
terapéuticos y de selección de las evidencias...”, contenida en la Guía de atención del ICBF (2007. Pp. 18, 58).

Se anticipan sesgos de información originados con la expresión "en contra del agresor", que irrumpe contraria a la presunción de inocencia, debido proceso e incluso al principio de imparcialidad y objetividad inherente al concepto de EF.

Al llegar a la UL, queda reducido a la somera formulación de cuestionario de preguntas previamente elaborado y luego tamizado por un Defensor de Familia; lo que no es propio de los protocolos mentados porque unidireccionan la búsqueda de información, descompensando el equilibro esencial de la investigación penal; se relega la confrontación de hipótesis características sine qua non de ellos.

\section{Categoría estructura.}

La UJ no determina los componentes de la EF, vacío que ahonda la distancia entre la concepción teórica y la definida por la praxis jurídica conocida por la experiencia propia. En lo teórico, la EF la integran varias fases con fines determinados en estricta sujeción al relato, su abordaje y el del NNA son menos intrusivos; en la práctica se admite pacíficamente una llana y reducida revelación mediante esquema pregunta-respuesta, con preguntas tipo que aparentan compaginar con las fases de uno u otro protocolo sin interacción lógica, que supere niveles básicos de descripción a los de comprensión y confrontación, necesarios para cimentar adecuadamente la evidencia.

Lo formal (estructura) cede a lo sustancial (información), y se olvida que la estructura de la EF traduce respeto por las garantías procesales, especialmente del menor, ya que desconocer lo formal habilita nuevas entrevistas para superar la escasa información recopilada en una primera intervención, asociada con relatos frágiles y sesgados que no alcanzan a tener suficiencia 
probatoria, sin descontarse la revictimización y obstrucciones que alteran el recuerdo original; desdibujando el verdadero acaecer, por fenómenos incidentes en la codificación de sucesos y posteriores evocaciones.

Apremia remarcar la poca importancia que con la premisa jurisprudencial "un mero formalismo" se da a la demanda que exige una entrevista con estructura compaginada con las subreglas tratadas en el Sistema Interamericano de Derechos Humanos, recogidos por la Corte Constitucional en Auto 009/2015.

En la UT, la citada Guía-ICBF (2007) alude como estructura: planeación y preparación, construcción de relación empática, introducción al tema, preguntas abiertas, preguntas específicas y cierre, etapas más ajustadas a criterios psicológicos, realzándola sobre la escueta formulación de preguntas. Aun facilitando un relato más neutral y mejores garantías procesales, sigue siendo insuficiente porque, según Hardy, van Leeuween y Lindberg (2003), citados por Arce y Fariña (2012), incluye "técnicas de interrogatorio que pueden resultar sugestivas" o traer información errónea.

En la UL, no se encontró información de relevancia.

\section{Categoría procedimiento.}

Fuerza a la estructura, le imprime eficaz servicio y dinamismo que reducen la brecha entre el deber ser de la EF y su praxis. La experiencia en el ámbito psicojurídico y lo encomiado desde la jurisprudencia sugiere que basta referenciar EF o términos asociados con protocolos como SATAC para admitirse que el proceso de entrevista fue de corte forense, al margen del real proceder.

Dicho esto se aprecia que la jurisprudencia no explicita el discurrir operativo de la EF, pero refina condiciones y actos psicojurídicos de hacer y no hacer, que acompasan con estándares 
técnico-científicos para recepcionar el relato, sin embargo no se muestran como unidad procedimental, por lo que su aplicabilidad queda al arbitrio del entrevistador forense; se pondera la necesidad de traer una sistemática inequívoca del proceder, como el uso de un protocolo estandarizado, según lo propone Maffioletti (2009).

Con la guía de 2007 la UT presenta el procedimiento de la entrevista paso a paso y con el lineamiento técnico para el programa especializado de atención a víctimas de ASI (Resolución ICBF 6022/2010) se aclara la confusión generada respecto a los roles a desempeñar frente a la EF por funcionarios administrativos o judiciales, propiciada por el modelo integral de abordaje de delito sexual en Colombia, que conlleva la participación de instituciones como Defensoría del Pueblo, Fiscalía General de la Nación (FGN), ICBF, INMLCF y define sus competencias y escenarios de acción.

Al margen de esta discusión, se señala la EF grabada en Cámara de Gesell por funcionario capacitado del CTI (excepcionalmente delegados administrativos del ICBF o de Comisaría de Familia), acompañado de Defensor de Familia desde la zona de grabación; ésta intervención resulta anti-técnica considerando que su profesión no lo habilita desde una perspectiva psicológica para comprender variables referidas al desarrollo evolutivo de los menores; por ejemplo, diferencias individuales, en el ambiente cultural en que se desenvuelven, señaladas por Perona, Bottoms y Sorenson (2005), y más específicamente "su desarrollo lingüístico y sus niveles de razonamiento y conocimiento..." citadas por Cantón y Cortés (2008) esto es, no lo hace idóneo y especializado, exigencia mencionada por la guía de UNICEF (2013); además porqué hay que evitar la presencia de terceras personas por los efectos nocivos que tiene en el relato, como lo señalan la guía 09 INMLCF (2010) y Masip y Garrido (2007). 
ENTREVISTA FORSENSE Y ABUSO SEXUAL INFANTIL

En la UL, la Ley 1652/13, "por la cual se dictan disposiciones acerca de la entrevista y testimonio en procesos penales de niños, niñas y adolescentes víctimas de delitos contra la libertad, integridad y formación sexuales", no hay hallazgos que depuren el procedimiento, solo advierte la revisión previa del cuestionario por parte del Defensor de Familia, recogiendo lo preceptuado en el artículo 150 de la Ley 1098/2006.

La experiencia muestra que esos cuestionarios direccionan el relato, rompen la neutralidad inherente a la EF y deforman la realidad por un mal sistema de interrogación, uso de preguntas e intervenciones inadecuadas, como lo explican Ibáñez (2009) y Bruck, Ceci y Hembrooke (2002); simultáneamente limitan o apartan al entrevistador de un actuar ceñido a los principios técnicos de aquella.

Este vacío indicaría que han de hacerse prevalecer las disposiciones internacionales en la materia, traídas a colación por la Corte Constitucional en Auto 009/2015, al citar una recomendación de la Asamblea General de las Naciones Unidas (1998) como estrategia para erradicar la violencia contra las mujeres en el marco de la prevención del delito y la justicia penal aplicable a la violencia sexual contra menores: “...introducir técnicas de investigación, sin ser degradantes para las mujeres objeto de violencia, y minimizando toda intrusión en su intimidad, estén a la altura de las prácticas más eficaces para la obtención de pruebas”.

\section{Categoría alcances.}

Categoría destacada, en tanto indica el impacto de la EF en el proceso penal; erige la necesidad de reclamar su adecuado ejercicio puesto que muestra la notoria significación que tiene a la hora de ajustar la decisión judicial sobre la ocurrencia del hecho delictivo y la responsabilidad del Juez implicado. 
Alrededor de esto la jurisprudencia trae sus mayores aportes, compila atributos que importan al derecho penal y a la psicología; se tocarán los mismos, no sin antes hacer claridad que en lo que corresponde a los primeros, las disquisiciones pueden resultar escuetas a razón del nivel de conocimiento que los autores tienen sobre la ciencia jurídica.

Para los $\mathrm{AL}$ se tiene que en todo caso la EF y su producto, el relato, adquieren unos alcances tanto en la etapa previa al juicio como en este. En aquella se dice que brinda a la fiscalía y la defensa elementos necesarios para direccionar su debate ante el Juez (Radicado 32829/2010), con la preparación del interrogatorio a formular al menor en juicio oral; no indica que sirva para orientar la investigación, por tanto deja de lado que el relato es criterio orientador en la búsqueda de la verdad del hecho, a la vez que lo integra al testimonio en juicio para examen en conjunto con otras pruebas; de ahí que buscar evidencia externa que diga del delito y que provenga del mismo relato no es cosa de menos, ya que esa evidencia ayudará a confirmar o desvirtuar el hecho, lo que se logra si se entiende que la obtención del relato no es acto pasivo de solo escucha, sino que implica ahondar en él explorando hipótesis alternas, porque de lo contrario se está incurriendo en sesgos confirmatorios (Juárez y Sala, 2011).

Al lado de aquel alcance concurre el del relato como prueba. En principio, dígase del sistema oral, venía admitiéndose que este no constituía tal, pero avanzando en la historia de la jurisprudencia fue perfilándose su potencial fuerza probatoria; allí se habla de pruebas indirectas (indiciaria y de referencia) y de plena prueba integrada al testimonio del menor en juicio.

En términos generales lo establecido es que como prueba indirecta el relato ingresa por el testimonio del entrevistador forense, por lo regular psicólogo, y la plena prueba cuando se integra por las técnicas de interrogatorio con el testimonio del menor, pero con valor suasorio diferente; es menor en el caso de la prueba de referencia e indiciaria que en la prueba plena, 
porque se asimilan a testimonios de oídas; empero ser este un criterio general de la valoración probatoria en el caso del ASI, la jurisprudencia ha propendido por señalar que no pueden asumirse como tal sino como testimonios directos, percibidos por un profesional especializado; de allí va naciendo la premisa indicadora de que el relato goza de capacidad suficiente para enervar la no ocurrencia del hecho, razón de más para reclamar la prudente y justa realización de una $\mathrm{EF}$ bajo estándares técnico-científicos, estas últimas, palabras propias del jurisprudente contenidas con especial relievancia en el Auto 009 de 2015 de la Corte Constitucional. MP Luis Ernesto Vargas, porque además alude reglas ajustadas al bloque de constitucionalidad.

Asociado a eso, surge un tema que importa tanto al derecho como a la psicología, el de la credibilidad del relato; marca en la probanza del hecho y se deriva de los testimonios vertidos por psicólogos en su rol de entrevistadores forenses (otras veces como peritos), como se ilustra en el Radicado 32868 de la Corte Suprema de Justicia, Sala Penal: "las entrevistas realizadas por las sicólogas [sic] y las conclusiones vertidas por ellas en sus correspondientes experticias, se advierten adecuadas y concordantes con lo que su profesión exige, razón por la cual debe ser acogidas en toda su extensión", destacando luego las opiniones dadas por una de estas profesionales: "El relato que me hizo la niña, lo encuentro a la luz de criterios científicos, coherente y creíble totalmente, precisamente en el caso del abuso sexual".

Lo anterior da lugar a crítica; al observar en la jurisprudencia se tiene que esas opiniones se fundamentan en criterios de credibilidad que no son estimados dentro de la literatura especializada en el tema de la evaluación del testimonio infantil referenciados por autores como Manzanero (2001), Cantón y Cortés (2008), Köhnken, Manzanero y Scott (2015) y Masip y Garrido (2007); en la argumentación de relato creíble, se habla de características como coherencia en aspectos centrales, detalles específicos, consistencia con otros relatos y en el 
contexto temporo-espacial que narró; lógica, secuencia lógica; ilación, narrativa sostenida de manera estable en el tiempo; ausencia de contradicciones o inconsistencias relevantes en distintas versiones y relato estructurado.

Se adicionan otros, como que el NNA entrevistado se ubica en tiempo y espacio, tiene capacidad de referir con exactitud las partes del cuerpo que le fueron tocadas/manipuladas, expuso relato con respaldo afectivo, se mostró sincero y no mostró tendencia a fantasear.

Así mismo, se encuentra que la jurisprudencia apoya la valía del testimonio en referentes teóricos asociados a la confiabilidad que adquiere el dicho del menor cuando ha sido víctima de atropellos sexuales conforme a estudios científicos o sustentados en investigaciones científicas o por el impacto que tiene el acto en su memoria (Davies, 2001).

Ante la crítica propuesta, conviene señalar que pende más, pero no exclusivamente, del actuar del psicólogo que del operador judicial, quien funda sus juicios convencido que el experto hizo un riguroso examen y evaluación del relato, sin observar la falta de rigor técnico científico subyacente a su opinión; no obstante la atiende en prevalencia del principio del interés superior del menor, que complica el sano ejercicio del principio de contradicción al que está sujeto el informe pericial por tratarse de un medio probatorio, como bien lo refieren Echeberúa, Muñoz y Loinaz (2011), "Por eso, el dictamen pericial debe contener la información manejada por el perito para llegar a las conclusiones expuestas (parte descriptiva), así como los criterios científicos utilizados por éste para valorar dichos datos (parte técnica)" (P. 153); aclarar la crítica no significa menosprecio por ese principio de raigambre constitucional, sino la necesidad de relievar la adherencia de opiniones a estándares técnico científicos.

Cabe precisar que el análisis adelantado deja entrever como se transfigura el testimonio del funcionario que recepcionó la $\mathrm{EF}$, como testigo de acreditación, (persona que concurre al juicio 
oral para informar sobre los elementos materiales probatorios que recauda), en prueba pericial, por el hecho que el mismo sea ofrecido por un psicólogo, descuidando las bases que rigen su construcción.

Ahora, aun cuando la UT no vincula directamente el tema de la credibilidad y validez del relato como alcance de la EF; si sugiere que está puede servir para efectos de la convalidación del ASI por parte del Juez, lo que en todo caso queda a la capacidad del funcionario que acompañó en acto para comunicarle las explicaciones y razonamientos que lo llevan a predicar la ocurrencia del ASI.

En cuanto a la UL, el alcance está definido por el uso excepcional del relato como prueba de referencia admisible, conforme al artículo 438 del CPP, adicionado por la Ley 1652/2013, que a pesar de los debates que ha generado, la declaratoria de exequibilidad de ésta, propicia su uso como tal; aquí entonces una razón más para fundamentar la necesidad de hacer igualmente exigible que la EF atienda a presupuesto técnico-científicos apropiados a cada caso concreto.

Llegando al final de la discusión y consideradas en conjunto las unidades de análisis que sirvieron al propósito de la investigación, junto con sus categorías y atributos, se determina que en el tema de la entrevista forense de uso para el recaudo del relato del menor sobre la alegación de ASI opera aún exigua definición, y que no se encuentran rigurosos indicadores que digan sobre el qué es, de qué se compone y cómo se realiza.

Esto conduce a determinar que en el discurrir del proceso penal irrumpen prácticas poco ajustadas en comparación con los referentes teóricos y técnicos-científicos apropiados desde la psicología del testimonio desde donde la EF, no se equipara en modo alguno con presentar un cuestionario para ser respondido por el NNA como lo presenta la Ley 1652/2013 sino que atiende a principios que dicen relación con la memoria humana, con los factores que la afectan, 
distorsionan o contaminan; entonces en la real aplicación se está desconociendo el rigor que atañe a la EF como medio técnico válido para recaudar el relato del menor, pese a sus alcances en la decisión judicial.

Esa realidad hace imperioso generar acciones que permitan re-significar la verdadera esencia de la EF, lo que en otras palabras traduce ajustar, incluso la misma ley que acoge su definición (concepto, estructura, procedimiento y alcances), a los estándares técnicos-científicos que se sugieren desde la psicología, así como acoplarla con los requerimientos de la prueba regulados en el Código Procesal Penal, esto es, desde una mira psicojurídica.

Se espera que el análisis efectuado sobre la EF, permita comprender que en el contexto de Colombia su normatividad es insuficiente; se carece de una protocolización que la defina como acto judicial a través de sus componentes y procedimientos judiciales y operativos. Se incoa la necesidad de reconocer las imprecisiones de la EF que por virtud de la praxis se han instaurado y hecho costumbre en Colombia, en detrimento de las garantías procesales de las partes en conflicto y de las reglas del saber científico construido desde la psicología.

Re-significar la EF, para una mejor praxis del derecho, es posible a través de acciones jurídicas y psicológicas; respecto a las primeras pueden ser factible alegaciones en sede de casación penal bajo el entendido que como lo sugiere el análisis hecho, como se practica la EF se está configurando una causal que habilita para demandas de casación por lo que el derecho denomina error de identidad por violación a las reglas de la ciencia y estimaciones de demandas de inconstitucionalidad de la Ley 1652/2013, en particular su literal d), artículo 2, puesto que haciendo uso de lo preceptuado en el Auto 09/2015, como se presenta la EF, se está propiciando un "acto puramente formal, o sin la seriedad y rigor requeridos para la defensa de los derechos de las partes procesales", vulnerando el derecho de verdad y justicia de las víctimas, el interés 
superior en punto a la no re-victimización que se hace más gravosa frente a entrevistas técnicamente inadecuadas, y el de defensa del procesado., en todo caso convocando la asidua participación del Colegio Colombiano de Psicólogos (COLPSIC), como entidad asociativa que conforme al artículo 12 de la Ley 1090 de 2006 debe propender por la defensa, fortalecimiento y apoyo del buen ejercicio de la psicología y porque es valor y principio del ejercicio de la psicología el respeto por los derechos humanos, donde se inscriben los derechos fundamentales que acompañan a los actores del conflicto en todo proceso penal.

En cuanto a las acciones psicológicas, se convoca a los psicólogos que desde una u otra parte intervienen en procesos penales, a mantener los estándares bioéticos y deontológicos que rigen el ejercicio de su profesión, y a las comunidades académicas y científicas a promover un catálogo de buenas prácticas que incluya directrices para que el psicólogo que funge como entrevistador forense actúe en observancia de los estándares técnico científicos de la EF, limite la práctica de cuestionarios preestablecidos como EF, se guíe por los protocolos que gozan de aval internacional para la correcta realización de entrevistas forenses en ausencia de propios, y reconozca los límites de su formación y actuación como entrevistador forense dado el impacto que sus opiniones vienen dejando en la administración de justicia.

\section{Referencias}

Arce, R y Fariña, F. (2006). Psicología del testimonio y evaluación cognitiva de la veracidad de testimonios y declaraciones. En J.C. Sierra, E.M. Jiménez, y G. Buela-Casal (Coords.), Psicología forense: Manual de técnicas y aplicaciones (pp. 563-601). Madrid, España: Biblioteca Nueva.

Arce, R y Fariña, F. (2012). La entrevista forense a niños, adultos, discapacitados. En S. Delgado (Dir.), F. Bandrés, y A. Tejerina (Coords.), Tratado de medicina legal y ciencias forenses: 
ENTREVISTA FORSENSE Y ABUSO SEXUAL INFANTIL

Vol. V. Pediatría legal y forense. Violencia. Víctimas (pp. 795-8179). Barcelona, España: Bosch.

Bernate F. (2004). El Código Penal Colombiano de 1890. Estudio Socio-Jurídico, 6 (2), 535-558.

Bruck, M., Ceci, S., y Hembrooke, H. (2002). The nature of children's true and false narratives. Developmental Review 22, 520-554.

Cantón, J. y Cortés, M. (2008). Guía para la evaluación del abuso sexual infantil. Madrid, España: Pirámide, 159

Cifuentes G., Rosa (2011). Diseños de proyectos de investigación cualitativa. Buenos Aires México: Noveduc, Centro de publicaciones educativas y material didáctico.

Davies, G. (2001). Is it possible to discriminate true from false memories? En G.M. Davies y T. Dalgleish (eds.), Recovered memories: Seeking the middle ground (pp.153-176). Chichester, Inglaterra: Wiley.

Dukala, K., y Polczyk, R. (2014). Value of content-based deception detection methods. European Polygraph, 8 (1), 29-44, DOI: 10.2478/ep-2014-0003.

Echeburúa, E., Muñoz, J., y Loinaz, I. (2011). La evaluación psicológica forense frente a la evaluación clínica: propuestas y retos de futuro. International Journal of Clinical and Health Psychology, 11 (1), 141-159.

Espinosa, A. (2012). Aportes de la Psicología Forense al abordaje de los delitos sexuales. Bogotá, Colombia: USAID - Defensoría del Pueblo.

Estado de Michigan. (1996). Protocolo de entrevista forense. Grupo de trabajo del Gobernador para la Justicia y el Menor.

Hernández, G. y Tapias, A. (2010). Maltrato Infantil: normatividad y psicología forense. Bogotá, Colombia: Universidad Santo Tomás. 
Hernández, R., Fernández, C. y Baptista, P. (2010). Metodología de la investigación (5 ${ }^{\mathrm{a}}$ ed.). México: McGraw-Hill.

Ibáñez, J. (2009). Psicología e investigación criminal: El Testimonio. Madrid, España: Dykinson.

ICBF (2007). Guía de atención a menores víctimas de violencia sexual. Bogotá, Colombia: ICBF.

ICBF (2010). Resolución 6022, Lineamiento técnico atención a NNA víctimas de violencia sexual. Bogotá, Colombia: ICBF. Recuperado de: http://www.icbf.gov.co/portal/page/portal/Descargas1/07ViolenciaSexualRes6022.PDF.

INMLCF (2010). Guía para la realización de Pericias psiquiátricas o psicológicas forenses en NNA presuntas víctimas de delitos sexuales. Bogotá, Colombia: INMLCF. Recuperado de: http://www.medicinalegal.gov.co/documents/48758/78081/G4.pdf/bc2dd6af-202b46ad-81a9-a4ad75210c8d

INMLCF (s.f.) Mesa interinstitucional. Acuerdos sobre la entrevista y evaluación forense en procesos judiciales por delitos sexuales. Bogotá, Colombia: INMLCF, pp. 1-4.

Juárez, J. y Sala, E. (2011). Entrevistando a niños preescolares víctimas de abuso sexual y/o maltrato familiar. Eficacia de los modelos de entrevista forense. Barcelona, España: Centro de Estudios Jurídicos y Formación Especializada.

Köhnken, G., Manzanero, A. y Scott, M. (2015). Análisis de la validez de las declaraciones: mitos y limitaciones. Anuario de Psicología Jurídica, 25, 13-19. Recuperado de http://www.redalyc.org.articulo.oa?id=315040291003.

Ley 1090 de 2006. Ejercicio de la profesión de psicología en Colombia.

Ley 1098 de 2006. De infancia y adolescencia en Colombia. 
Ley 1652 de 2013. Acerca de la entrevista y el testimonio de menores en procesos penales.

Ley 599 de 2000. Código Penal Colombiano.

Ley 906 de 2004. Código de Procedimiento Penal.

Maffioletti, F. (2009). La entrevista forense a la víctima de delitos sexuales. Revista Jurídica del Ministerio Publico, 38, 199-228.

Maffioletti, F. y Huerta, S. (2012). Guía de Entrevista Investigativa con Niños, Niñas y Adolescentes Víctimas de Delitos Sexuales. Santiago, Chile: Unidad Especializada en Delitos Sexuales y Violentos, Fiscalía Nacional del Ministerio Público.

Manzanero, A. (2001). Procedimientos de evaluación de credibilidad de las declaraciones de menores víctimas de agresiones sexuales. Revista de Psicopatología Clínica, Legal y Forense, 1 (2), 51-71.

Masip, J. y Garrido, E. (2007). La evaluación del abuso sexual infantil. Análisis de la validez de las declaraciones del niño. Sevilla, España: Eduforma.

Observatorio de Sentencias Judiciales (2016). Alianza de instituciones feministas. Recuperado de http://www.articulacionfeminista.org.

Piñuel, J. (2002). Epistemología, metodología y técnicas del análisis de contenido. Universidad Complutense de Madrid, España, 2.

Perona, A., Bottoms, B., y Sorenson, E. (2005). Research-based guidelines for child forensic interviews. Journal of Aggression, Maltreatment \& Trauma, 12 (3-4), 81-130. DOI:10.1300/J146v12n03_04.

Polo, L. y Cabarcas, A. (2013). Valor probatorio del testimonio de un menor en un proceso penal de abuso sexual. Pensamiento Americano 6 (10), 71-81. 
Ruiz, A. (2004). Texto, testimonio y metatexto. El análisis de contenido en la investigación en educación. En A. Jiménez y A. Torres (comp.), La práctica investigativa en ciencias sociales (pp. 45-47). Bogotá, Colombia: Universidad Pedagógica Nacional.

Soria, M. A. (2007). Manual de Psicología jurídica e investigación criminal. Madrid, España: Pirámide.

UNICEF (2013). Guía de las buenas prácticas para el abordaje de niños/as, adolescentes víctimas o testigos de abuso sexual y otros delitos. Buenos Aires, Argentina: UNICEF ADC. 